\title{
Expression and regulation of COP1 in chronic lymphocytic leukemia cells for promotion of cell proliferation and tumorigenicity
}

\author{
CHUNLING FU ${ }^{1-3^{*}}$, YANQING GONG $^{1 *}$, XUANXUAN SHI $^{1 *}$, \\ HENGLIANG SHI ${ }^{4}$, YAN WAN ${ }^{1}$, QINGYUN WU ${ }^{1,2}$ and KAILIN XU ${ }^{1-3}$ \\ ${ }^{1}$ Blood Diseases Institute, Xuzhou Medical College, Xuzhou, Jiangsu 221002; \\ ${ }^{2}$ Key Laboratory of Bone Marrow Stem Cell, Xuzhou, Jiangsu 221002; Departments of ${ }^{3}$ Hematology, \\ and ${ }^{4}$ Neurosurgery, The Affiliated Hospital of Xuzhou Medical College, Xuzhou, Jiangsu 221002, P.R. China
}

Received October 11, 2015; Accepted November 18, 2015

DOI: $10.3892 /$ or.2015.4526

\begin{abstract}
Chronic lymphocytic leukemia (CLL) is the most common leukemia in Western countries, and mainly originates from an accumulation of abnormal B cells caused by the dysregulation of cell proliferation and apoptosis. The aberration of proliferation-related gene in CLL cells induces cell arrest at G0/G1 phase, or a small section shows rapid cell growth, which further complicates the pathogenesis of CLL. The constitutively photomorphogenic 1 (COP1), as an E3 ubiquitin ligase, is involved in many biological processes in mammalian cells, but its role in chronic lymphocytic leukemia (CLL) progression remains unclear. In the present study, we analyzed the expression of COP1 in peripheral blood mononuclear cells (PBMCs) from 23 CLL patients and 3 healthy donors. The observed upregulated expression of COP1 in CLL patients was positively correlated with CLL clinical stage and ZAP-70 expression, but not del(13q14) and del(17q-). Overexpression of COP1 significantly promoted cell colony formation and proliferation, especially contributing to the accumulation of cells in S-phase by inhibition of FoxO1 and p21. Moreover, overexpression of COP1 accelerated tumorigenicity of HG3 cells and promoted xenograft growth. Therefore, the present study revealed that COP1 plays an important role in CLL cell proliferation and tumorigenicity, and may be a useful indicator of the chronic lymphocytic leukemia processes.
\end{abstract}

Correspondence to: Professor Kailin Xu, Blood Diseases Institute or Department of Hematology, the Affiliated Hospital of Xuzhou Medical College, 84 West Huaihai Road, Xuzhou, Jiangsu 221002, P.R. China

E-mail: lihmd@163.com

${ }^{*}$ Contributed equally

Key words: chronic lymphocytic leukemia, constitutively photomorphogenic 1, HG3 cells, proliferation, tumorigenicity

\section{Introduction}

CLL is the most common form of leukemia in adults, and is particularly common in Western countries (1). However, the incidence of this disease is gradually increasing also in China (2). It is characterized by an accumulation of abnormal $\mathrm{B}$ cells, resulting from the dysregulation of proliferation and apoptosis $(3,4)$. Despite attempts to develop new treatment strategies, CLL is currently incurable $(5,6)$.

Recent studies have suggested that most CLL cells are arrested in the G0/G1 phase of the cell cycle. This is caused, in part, by the aberration of cell cycle related gene such as cyclin D family, which blocks the transition of $\mathrm{G} 1$ to $\mathrm{S}(5,7,8)$. However, there are several studies supporting that a small fraction of CLL cells display rapid growth (9-11), which are accumulated in special structures of the bone marrow and lymphatic nodes, the proliferation centers (12). CLL cells in those areas are characterized by a higher expression of Ki-67, survivin and Bcl-2 factors typically associated with proliferation (13).

COP1 was first defined as a central regulator of photomorphogenic development in plants (14), later in mammals (15). It consists of 3 functional domains, a RING-finger domain, a coiled-coil domain, and a WD40 domain and is highly conserves from plants to mammals (16). COP1 possesses E3 ubiquitin ligase activity, which targets key transcription factors for proteasome-dependent degradation and plays an important function in many biological responses in mammals (17). As reported, the substrates of mammalian COP1 include c-Jun, ETV1, p53, acetyl-CoA carboxylase (ACC) (18), TORC2 and FoxO1, suggesting that COP1 is involved in tumorigenicity, lipid metabolism and gluconeogenesis (19-24). COP1 is frequently overexpressed in breast, ovarian, hepatoma and gastric cancer, and promotes tumorigenicity via inhibition of p53 activity (25-27). In contrast, COP1 targets CCAAT/enhancer-binding protein $(\mathrm{C} / \mathrm{EBPa})$ for degradation and induces acute myeloid leukemia via Trib1 (28), while COP1 constitutively regulates c-Jun protein stability and functions as a tumor suppressor in mice (29). Although COP1 is involved in many biological processes 
in mammalian cells, its role in tumorigenicity remains controversial (18). Besisdes, the relative abundance and physiological function of COP1 is unclear in the progression of CLL.

In the present study, we addressed the role of COP1 in CLL cell proliferation and tumorigenicity. We collected 23 samples from CLL patients at diagnosis, and assessed the correlation between the expression of COP1 and clinical stage, chromosomal abnormalities and prognostic indicators in CLL patients. We found that the level of COP1 was positively correlated with clinical staging of CLL patients and ZAP-70 expression. We also showed that overexpression of COP1 facilitated to cell colony formation and proliferation, further promoted cell cycle transition from G0/G1 to S phase by inhibition of the FoxO1 and p21 activity. Moreover, overexpression of COP1 accelerated tumorigenicity and promoted xenograft growth. These results suggest that COP1 may play a positive role in the progression of CLL, and that determination of its expression may be helpful for monitoring condition changes in CLL patients.

\section{Materials and methods}

Patients and samples. CLL samples were obtained from the Affiliated Hospital of Xuzhou Medical College according to the diagnostic criteria for CLL between August 2013 and July 2015, while 3 healthy volunteers served as a normal control. PBMCs were isolated from heparinized blood obtained from 23 CLL patients, and normal B cells were separated from healthy donor via $\mathrm{CD} 19^{+}$labeled MicroBeads according to the manufacturer's instructions.

All procedures performed in studies involving human participants were in accordance with the ethical standards of the institutional and/or national research committee and with the 1964 Helsinki declaration and its later amendments or comparable ethical standards.

Cell line and reagent. CLL cell line HG3, gifted by Anders Rosén (Linköping University, Sweden) (30), was cultured in RPIM-1640 medium supplied with $10 \%$ (v/v) fetal bovine serum (FBS; Gibco, Grand Island, NY, USA) at $37^{\circ} \mathrm{C}$ in $5 \% \mathrm{CO}_{2}$ incubator (Thermo Fisher Scientific, Waltham, MA, USA). COP1 antibody was purchased from Bethyl Laboratories, Inc. (Montgomery, TX, USA). Polyclonal antibodies specific for FoxO1 and ZAP-70 were purchased from Santa Cruz Biotechnology (Santa Cruz, CA, USA), and monoclonal antibodies for p21 and $\mathrm{Ki}-67$ were, respectively, purchased from Cell Signaling Technology (Danvers, MA, USA) and Abcam (Cambridge, UK), anti-GAPDH was purchased from EnoGene Biotech Co., Ltd. (Nanjing, China). Goat anti-rabbit IgG and rabbit anti-mouse IgG were obtained from Sigma-Aldrich (St. Louis, MO, USA). Cell Counting kit (CCK-8) was from Dojindo Molecular Technologies (Xiongben, Japan), CD19+ labeled MicroBeads were from Miltenyi Biotec (Auburn, CA, USA).

Animals. Female BALB/C nude mice of 6 weeks of age were obtained from Vital River Laboratories Co., Ltd. (Beijing, China). All experimental procedures were performed in accordance with the guidelines for laboratory animals estab- lished by the Xuzhou Medical College Animal Care and Use Committee.

Plasmid construction and lentiviral production. For overexpression of COP1, the COP1 cDNA was a gift from Han Jiahuai laboratory and cloned into lentiviral plasmid pWPXLd-GFP. For viral production, the pWPXLd-GFP-COP1 plasmid was cotransfected into 293FT human embryonic kidney cells together with packaging and envelope protein plasmids with PolyJet (Signagen Laboratories, Gaithersburg, MD, USA) as described in the manufacturer's protocol. Culture supernatants containing lentiviral particles were harvested $72 \mathrm{~h}$ after transfection and used for infection.

Establishment of the stable cell lines. For stable overexpression of COP1, the HG3 CLL cells were infected with pWPXLd-GFP or pWPXLd-GFP-COP1 viruses, respectively. Forty-eight hours after infection, the cells were continuously cultured in the medium containing $2.5 \mu \mathrm{g} / \mathrm{ml}$ of puromycin (Sigma). The surviving cells were cultured into cell lines stably expressing GFP or GFP-COP1.

Soft-agar clone formation assay. The CLL cells were harvested and pipetted to single-cell suspension with 1640 medium containing $20 \%$ FBS in a given concentration at $1 \times 10^{4} / \mathrm{ml}$. Melted $1.2 \%$ agar by microwave was mixed with pre-warmed 1640 medium containing 20\% FBS and put into a 6-well plate for it to become solid (total volume $1 \mathrm{ml} /$ well), and then, melted $0.6 \%$ agar was mixed quickly with cell suspension equally and added the bottom solid agar (total volume $1 \mathrm{ml} /$ well). Additional $100 \mu \mathrm{l}$ medium was added to the top layer and incubated for 2 weeks, at $37^{\circ} \mathrm{C}$. The number of colonies was calculated under a microscope in 3 -wells of two groups.

CCK-8 analysis for cell vitality. Three thousand cells in $100 \mu \mathrm{l}$ of medium were seeded into 96 -well plates with three replicates. CCK- 8 reagent $(5 \mu \mathrm{l})$ was added into each well at the time-point $0,6,12,18,24$ and $30 \mathrm{~h}$. Following incubation for additional $4 \mathrm{~h}$, the cells were exposed to measure the absorbance at $450 \mathrm{~nm}$ by a microplate reader (Wellscan MK3; Labsystems Dragon, Helsinki, Finland).

Cell cycle analysis. The normal cultured and serum starved CLL cells were collected and fixed in $70 \%$ ethanol on ice for $10 \mathrm{~min}$, rinsed with PBS and incubated with $100 \mathrm{mg} / \mathrm{ml}$ RNase A $(0.25 \mathrm{mg} / \mathrm{ml})$ for $15 \mathrm{~min}$. After washing with PBS two times, the cells were further incubated with $50 \mu \mathrm{g} / \mathrm{ml}$ propidium iodide (PI) at room temperature for $10 \mathrm{~min}$, and then exposed to cell cycle analysis.

Immunoblotting. The CLL patient samples and cultured cells were collected and proteins extracted for western blotting. Equal amount of protein lysates were subjected to $10-12 \%$ SDS-PAGE and then transferred to $0.45 \mu \mathrm{m}$ pore size PVDF membrane (Millipore, Billerica, MA, USA). After blocking with $5 \%$ non-fat milk, the membrane was probed with primary antibodies at $4^{\circ} \mathrm{C}$ overnight and secondary antibodies at room temperature for $1 \mathrm{~h}$. Bound antibodies were detected by the Pierce ECL Plus Western Blotting Substrate (Thermo Fisher 

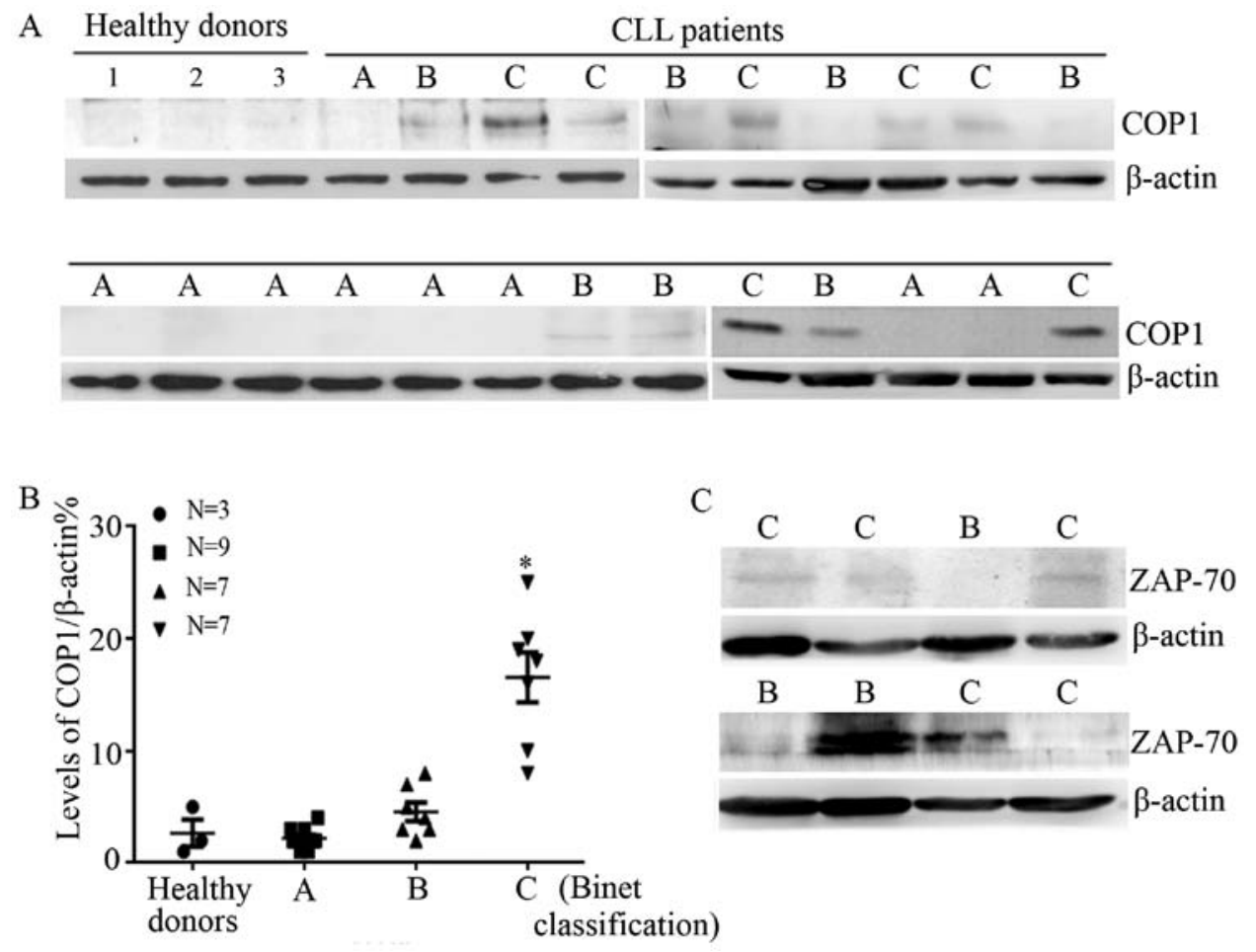

Figure 1. Detection of the expression of COP1 and ZAP-70 in CLL patients. (A) CLL cells and normal B cells were collected from 23 CLL patients and 3 healthy donors and exposed to detect the expression of COP1 by western blotting. (B) Semi-quantitative calculation of the western blotting bands via ImageJ and statistic analysis of correlation between the COP1 expression and CLL clinical stage. (C) The expression of ZAP-70 was detected and partially showed in 23 CLL samples.

Scientific) and visualized by ImageQuant LAS 4000 (GE, Fairfield, CT, USA).

Tumor formation in $B A L B / C$ nude mice. Experiments were performed with 6-weeks-old female BALB/C nude mice $(\mathrm{n}=6)$. Both HG3-GFP and HG3-COP1 cells were cultured in 10 -cm dishes in RPMI-1640 medium with 10\% FBS and gently harvested by washing with PBS. The cells were centrifuged and re-suspended into a suitable concentration at $5 \times 10^{7} / \mathrm{ml}$. An equal volume of the cell suspension $(100 \mu \mathrm{l})$ was inoculated subcutaneously in the right flank of the mice. At day 14 after inoculation, tumor size was assessed by external measurement of the length (L) and width (W) of the tumors using a vernier caliper. Tumor volume was calculated by using the following equation: $\mathrm{TV}=\left(\mathrm{L} \mathrm{x} \mathrm{W}^{2}\right) / 2$. After 30 days, the tumor was isolated and fixed in $4 \%$ PFA at $4^{\circ} \mathrm{C}$ overnight and dehydrated gradient in sucrose, after entrapment with embedding material, the tumor was cut into frozen slices.

Immunohistochemistry. Briefly, tissue sections $(\sim 2 \mathrm{~mm})$ were deparaffinized in xylene, rehydrated in graded alcohols $(100,95,85$ and $75 \%)$ and washed in distilled water. The immunohistochemistry was performed according to the S-P immunohistochemistry kit (Maixin-Bio, Fuzhou, China). For each tissue specimen, three horizons were randomly selected and photographed by microscopy for statistical analysis.

Statistical analysis. The results are representative of experiments repeated at least three times and quantitative data were expressed as means \pm SEM. Student's t-test was used to analyze the difference between test samples and control, and Fisher's exact test was used for correlation analysis of small samples. $\mathrm{P}<0.05$ was considered statistically significant, and $\mathrm{P}<0.01$ as very significant. All statistical analyses were performed using Graphpad Prism 6.0.

\section{Results}

Expression of COP1 positively correlates with Binet classification in CLL patients. We analyzed the expression of COP1 in normal and CLL patients by isolating mononuclear cells from peripheral blood and extracting protein for western blotting. Fig. 1A shows that COP1 levels were high in CLL patients compared with normal donors. Further statistical analysis indicated that COP1 levels were significantly increased in CLL cells of Benit $\mathrm{C}$ patients $(\mathrm{P}<0.05)$ (Fig. 1B).

We next measured the incidence of del(13q14) and del(17q-), as well as ZAP-70 expression to examine whether the expression of COP1 was correlated with chromosomal abnormality or molecular marker in CLL patients. As shown in Table I and Fig. 1C, no apparent correlation was observed between $\mathrm{COP} 1$ expression and del(13q14) $(\mathrm{P}=0.28)$, del(17q-) $(\mathrm{P}=0.39)$. Nevertheless, the expression of COP1 was strongly positively correlated with ZAP-70 expression $(\mathrm{P}=0.02)$.

Overexpression of COP1 contributes to the proliferation of HG3 cells. We further investigated the role of COP1 in CLL progression by transfecting HG3 cells with lentiviruses expressing GFP or GFP-COP1. After sustaining the selection with puromycin, flow cytometry and western blotting showed the infected efficiency reached $>95 \%$ (Fig. 2A-C). Thereafter, 
A

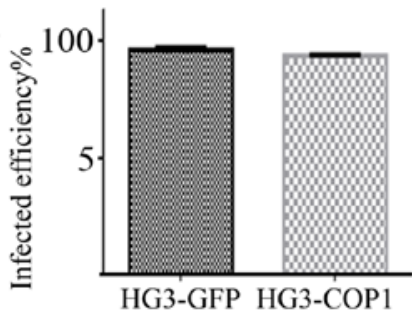

$\mathrm{D}$

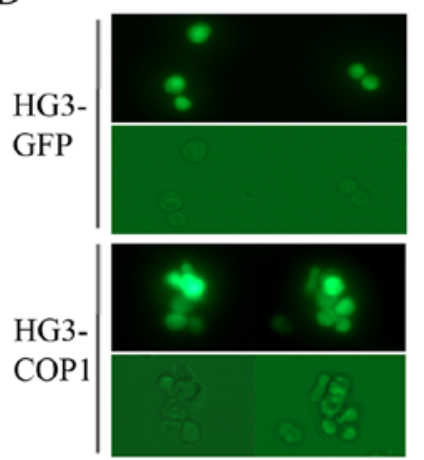

B

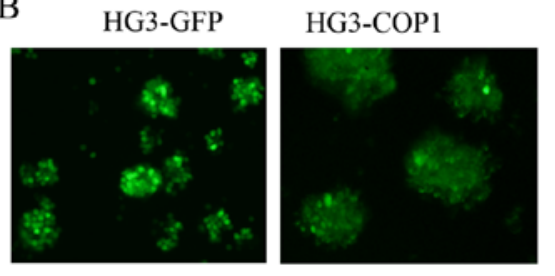

$\mathrm{C}$

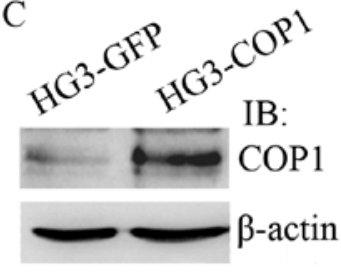

E

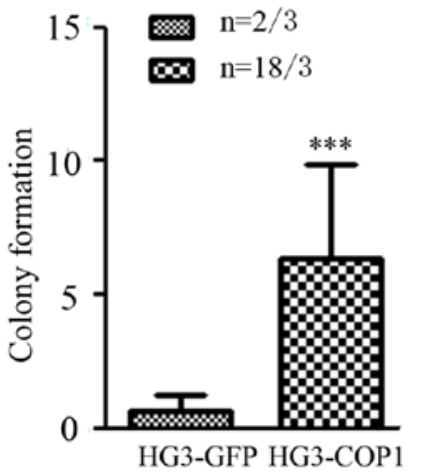

$\mathrm{F}$

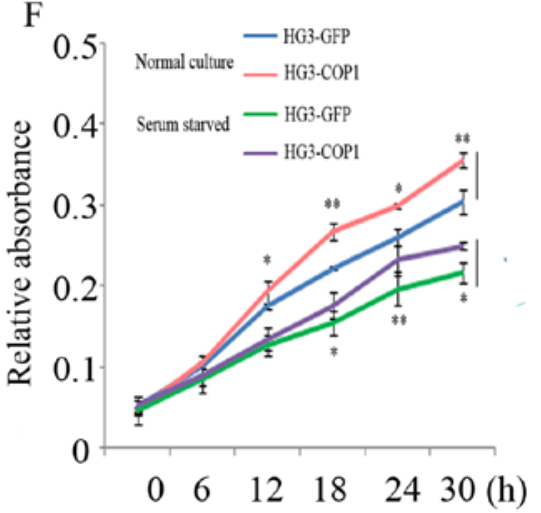

Figure 2. Overexpression of COP1 promotes HG3 cell colony formation and proliferation, as well as increases cell vitality. (A and B) pWXLd-GFP or pWXLd-GFP-COP1 plasmids were packed into lentivirus particles and infected HG3 cells, separately. (C) After sustained selection with puromycin, the infected efficiency was detected via flow cytometry, and the cellular protein was extracted and subjected to SDS-PAGE for examining the expression of COP1. (D and E) The well-established HG3-GFP and HG3-COP1 cells were grown in soft agar to observe the colony formation, after 2 weeks, the number of colonies was calculated under a microscope in 3-wells of two groups. (F) The HG3-GFP and HG3-COP1 cells were grown in a 96-well plate at 1x10 ${ }^{3}$ cells/well, the cells vitality was examined when incubated with CCK- 8 reagent at designed time-points. The relative absorbance was measured by a microplate reader every $24 \mathrm{~h}$.

Table I. Correlation analysis between the expression of COP1 and $\operatorname{del}(13 \mathrm{q} 14)$, del(17q-),ZAP-70 expression in CLL patients.

\begin{tabular}{lccc}
\hline & \multicolumn{2}{c}{ COP1 expression } & \\
\cline { 2 - 3 } & Low $(\mathrm{P}<6.8 \%)$ & High $(\geq 6.8 \%)$ & P-value \\
\hline $\begin{array}{l}\text { ZAP-70 expression } \\
\text { Positive }\end{array}$ & 1 & 5 & 0.02 \\
Negative & 13 & 4 & \\
13q14 & & & 0.28 \\
Positive & 1 & 2 & \\
Negative & 13 & 7 & \\
17q- & & & 0.39 \\
Positive & 0 & 1 & \\
Negative & 14 & 8 & \\
\hline
\end{tabular}

The expression level of COP1 was determined by calculation of the western blotting bands via ImageJ. The patients were divided into two groups according to the mean value of COP1 level, and the association assessed between COP1 expression and del(13q14), (17q-), as well as ZAP-70 expression.

the well-established HG3-GFP and HG3-COP1 cells were first grown in soft agar to observe the colony formation. During the cultivation, the two groups of CLL cells grew slowly in soft agar compared to complete culture medium. Notably,
HG3-COP1 cells proliferated slowly and formed cell colonies, while most HG3-GFP cells did not growth or proliferate except for very few cells. In the further observation for two weeks, there were 18 colonies in HG3-COP1 vs. 2 small colonies in HG3-GFP group (Fig. 2D and E).

Then the growth rates of both cells were measured quantitatively using a CCK- 8 kit at $0,6,12,18$ and $24 \mathrm{~h}$ after lentivirus infection. HG3-COP1 cells showed significantly higher absorbance compared with HG3-GFP cells in normal cultivation or serum starvation treatment, suggesting increased cell viability (Fig. 2F) $(\mathrm{P}<0.05)$.

Overexpression of COP1 promotes the transition of $\mathrm{HG} 3$ cells from G1 to $S$ phase. To investigate the role of COP1 in cell cycle progression, cells were collected and stained with propidium iodide for cell cycle analysis via flow cytometry. Similar distribution of the cell cycle were observed in two groups (30-35\% in $\mathrm{G} 1,41-50 \%$ in $\mathrm{S}$ and $20-24 \%$ in $\mathrm{G} 2 / \mathrm{M}$ phases) after normal cultivation for $12 \mathrm{~h}$, while $\mathrm{S}$-phase HG3-COP1 cells were $55 \pm 1 \%$ compared with $46 \pm 0.9 \%$ of HG3-GFP cells after $24 \mathrm{~h}$, displaying a faster and more proliferative phenotype $(\mathrm{P}<0.05)$. Moreover, it can be seen that HG3-GFP cells were grown arrested at G0/G1 phase (38 \pm 1 and $39 \pm 3 \%$, respectively) upon serum starvation for 12 or $24 \mathrm{~h}$ compared to untreated cells $(30 \pm 1 \%)$, showing an increase of 8 and 9\%, while in G0/G1-phase HG3-COP1 cells (27.6 44 and $28.4 \pm 1 \%$, respectively) no changes were observed with the same treatment compared with cells at $0 \mathrm{~h}$ (25.5 $\pm 2 \%)$ (Fig. 3A and B). 
A
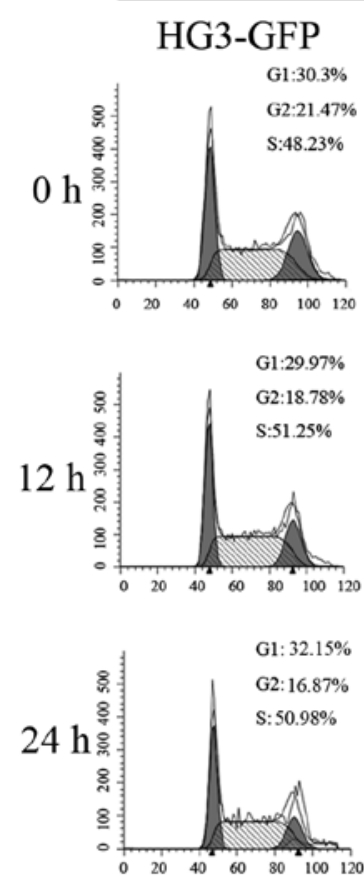

Normal culture

HG3-COP1
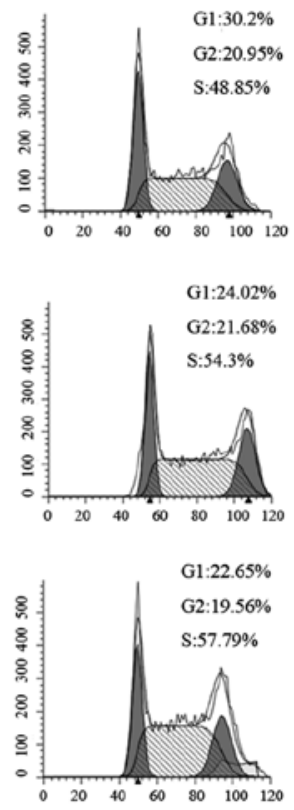

Serum starved
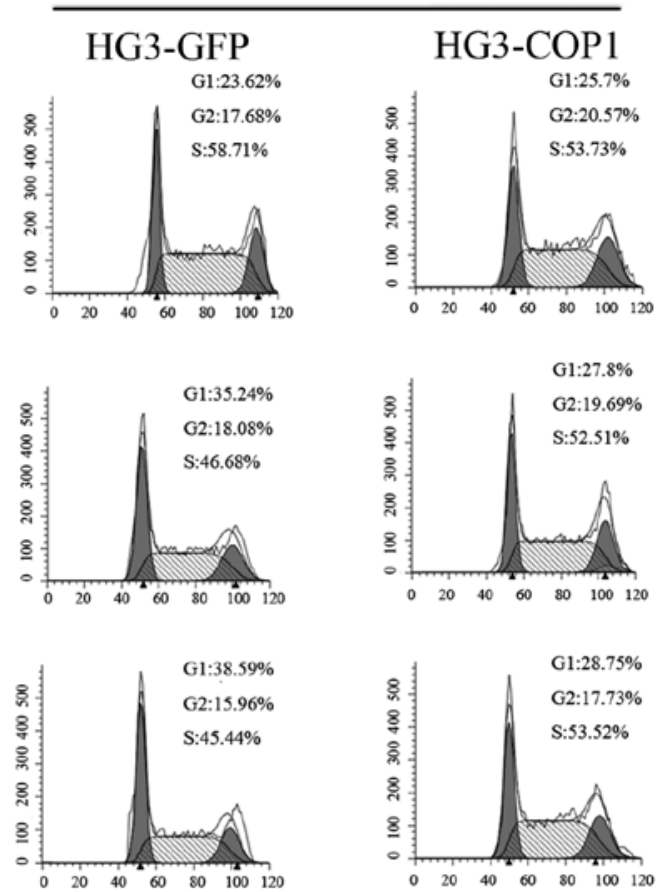

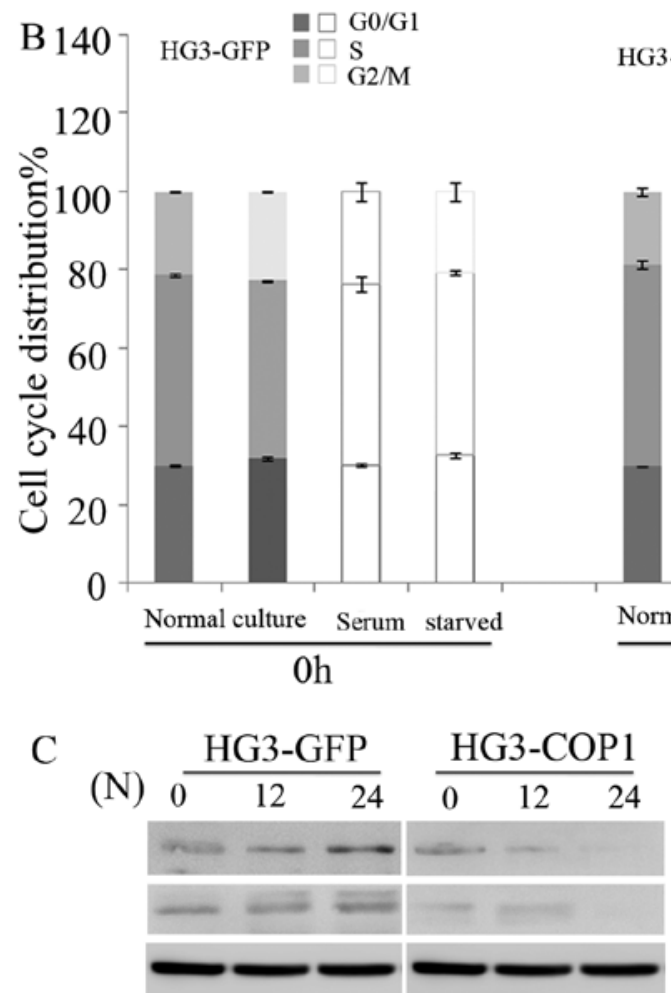

$\begin{array}{rl}\mathrm{HG} 3-\mathrm{COP} 1= & \mathrm{G} 0 / \mathrm{G} 1 \\ \mathrm{~S} & \mathrm{G} 2 / \mathrm{M}\end{array}$
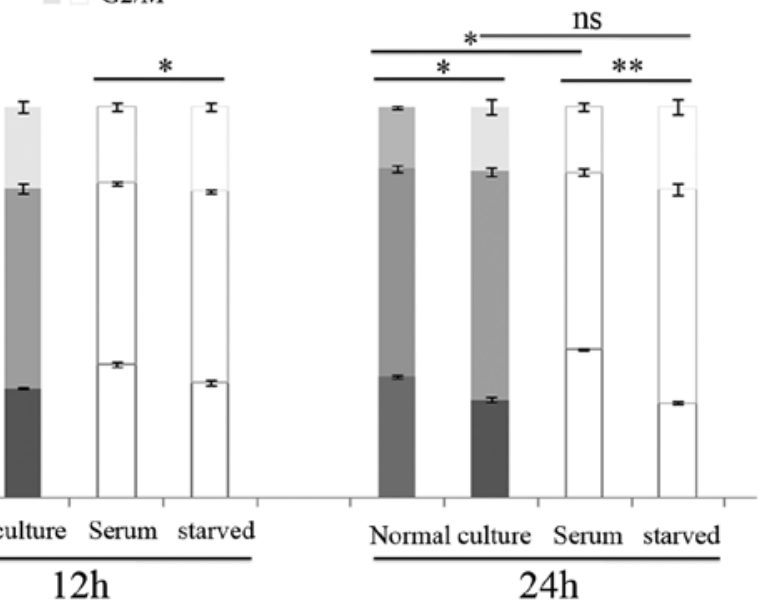

$12 \mathrm{~h}$

IB:

(S)

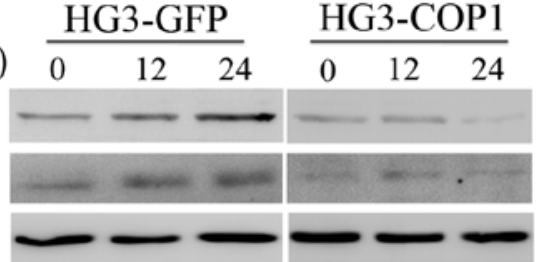

(h)

FoxO1

p21

GAPDH

Figure 3. Overexpression of COP1 promotes accumulation of S-phase cells. (A) The HG3-GFP and HG3-COP1 cells with the same concentration were grown in a 6-well plate under normal cultivation or serum starvation. After $24 \mathrm{~h}$, the cells were collected and stained with PI for cell cycle analysis by flow cytometry. (B) Three independent experiments were performed for statistical analysis of the distribution of the cell cycle. (C) The protein was exposed to detect the expression of FoxO1 and $\mathrm{p} 21$ ( $\mathrm{N}$ and $\mathrm{S}$ represent normal cultivation and serum starvation, respectively).

To study the underlying mechanisms responsible for the fast growth of HG3-COP1 cells, we detected the expression of FoxO1, as a polyubiquitinated substate of COP1, and its downstream genes associated with cell cycle progression. Western blotting showed that FoxO1 and p21 level in HG3 cells were significantly inhibited after overexpression of COP1 in normal cultivation for $24 \mathrm{~h}$. In addition, we found that raising COP1 level blocked the elevation of FoxO1 and p21 level upon serum starvation treatment (Fig. 3C).

Overexpression of $\mathrm{COP1}$ promotes tumorigenicity of $\mathrm{HG} 3$ cells. To study the effect of COP1 in CLL cells in vivo, 
A

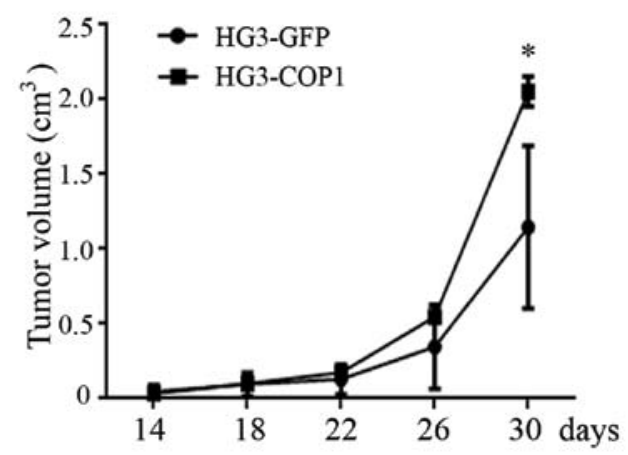

$\mathrm{C}$

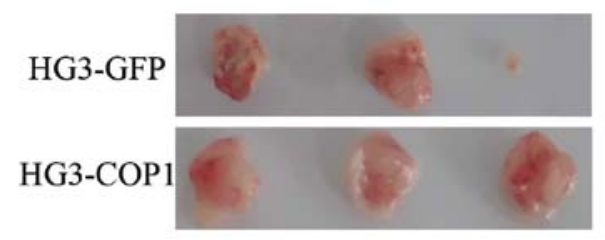

E

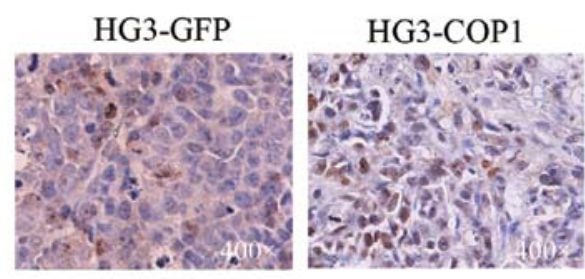

B

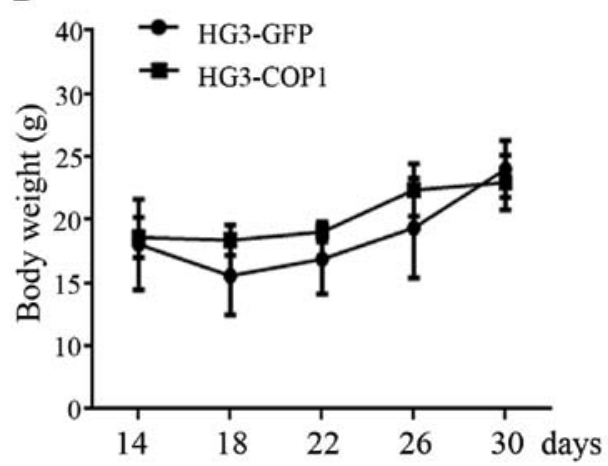

$\mathrm{D}$

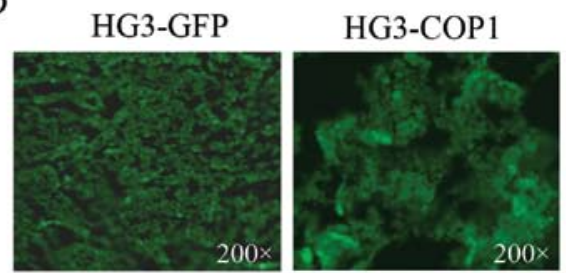

$\mathrm{F}$

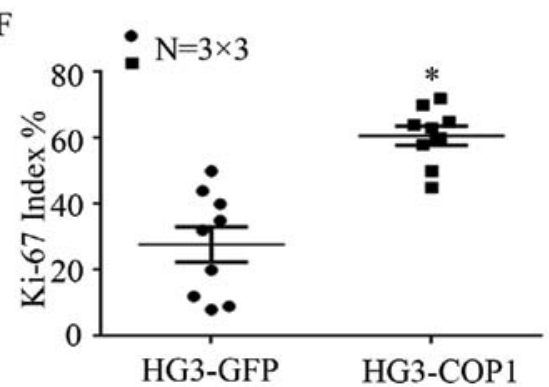

Figure 4. The formation of xenografts in BALB/C nude mice. (A and B) The HG3-GFP and HG3-COP1 cells were prepared to appropriate concentration at $5 \times 10^{7} / \mathrm{ml}$ and inoculated subcutaneously in the right flank of the BALB/C nude mice. The tumor volume and body weight were measured every four days. (C and D) The tumors were isolated and cut into slices for observation after 30 days. (E and F) The tumor tissue was stained with Ki-67 and the positive cell numbers were calculated. For each tissue specimen, three horizons were randomly selected and photographed under the microscope for statistical analysis.

Table II. Tumorigenicity of HG3-GFP and HG3-COP1 cells in $\mathrm{BALB} / \mathrm{C}$ nude mice.

\begin{tabular}{lcccccc}
\hline & & \multicolumn{5}{c}{ Tumorigenicity } \\
\cline { 3 - 7 } Groups & $\mathrm{N}$ & 14 & 18 & 22 & 26 & 30 (Days) \\
\hline HG3-GFP & 3 & $1 / 3$ & $2 / 3$ & $2 / 3$ & $3 / 3$ & $3 / 3$ \\
HG3-COP1 & 3 & $3 / 3$ & $3 / 3$ & $3 / 3$ & $3 / 3$ & $3 / 3$ \\
\hline
\end{tabular}

female BALB/C nude mice were subcutaneously inoculated with equal numbers of HG3-GFP or HG3-COP1 cells in the right flank. At day 14 after inoculation, all three mice in the HG3-COP1 group had developed tumors, whereas, only two mice inoculated with HG3-GFP cells developed tumors, and the third mouse developed a tumor at day 26 after inoculation (Table II).

Moreover, the tumor size and body weight of mice were measured once per four days. The mice inoculated with HG3-COP1 cells showed remarkably increased tumor growth, the final tumor volume was $2.2 \mathrm{~cm}^{3}$, significantly higher than control ones with $1.4 \mathrm{~cm}^{3}$ of tumor volume (Fig. 4A). Moreover, the body weight was not changed in these mice (Fig. 4B). Thirty days after measurement, both groups had developed tumors (Fig. 4C and D), whereas, the tumor tissue from HG3-COP1 group showed stronger Ki-67 staining compared with the control (Fig. 4E and F).

\section{Discussion}

CLL is the most common human leukemia, representing $30 \%$ of all cases (31), which are characterized as accumulation of B cells due to an imbalance between activation of cell proliferation and inhibition of apoptosis $(3,4)$. Most CLL B cells are characterized by high expression of the p27 protein, which blocks the cell cycle progression (32). Interestingly, a small but significant fraction of all leukemic cells proliferates with higher Ki-67 expression (33), this discovery makes the pathogenetic mechanisms of CLL more complicated.

COP1 has been reported to be expressed in most tumors and normal matching tissues except for partial deletions $(<8 \%$ in all cancer types analyzed) in various tumors (29). COP1, as 
an oncogene, plays an important role in breast, ovarian, gastric and hepatocellular carcinoma, its high expression is significantly correlated with poor survival in gastric cancer patients $(13,17,18)$. In the present study, we found that COP1 expression was upregulated in human Benit C-phase CLL patients compared with normal donors. Moreover, this expression was positively correlated with CLL clinical stage and ZAP-70 expression, suggesting that it may be an important indicator of CLL progression.

A recent study showed that COP1 silencing greatly suppressed the proliferation of human hepatocellular carcinoma cells, as well as tumorigenicity (17). While overexpression of COP1 accelerates development of acute myeloid leukemia by affecting the upstream tumor suppressor $\mathrm{C} / \mathrm{EBP} \alpha$, suggesting its ligase activity is crucial for leukemogenesis (33). Conversely, Migliorini et al (29) reported that a significant decrease or deletion of COP1 expression are found in prostate carcinoma or ALL (acute lymphocytic leukemia), respectively. COP1 knockdown promotes prostate carcinoma cell proliferation by increasing the basal c-Jun protein levels. In particular, COP1 deficiency stimulates mouse embryonic fibroblast proliferation in a c-Jun-dependent manner, and Cop1 hypomorphic mice spontaneously developed lymphomagenesis when exposed to radiation induction (21). Notably, we found that overexpression of COP1 significantly facilitated colony formation and proliferation of HG3 cells. In particular, it promoted the cellular transition from $\mathrm{G} 1$ to $\mathrm{S}$ phase by downregulation of FoxO1. As known, FoxO1, as a substrate of COP1, directly targets p21 to regulate the cell cycle process (34). The results showed upregulation of COP1 also inhibited p21 level in normal cultivation, and blocked the elevation of FoxO1 and p21 level upon serum starvation. Importantly, the overexpression of COP1 accelerated tumorigenicity of HG3 cells and promoted xenograft growth.

In conclusion, the present study revealed that COP1 is an important indicator of CLL processes, while its expression was shown to be associated with CLL clinical stage and ZAP-70 expression. Moreover, overexpression of COP1 promoted the cell proliferation and tumorigenicity. These results suggest that COP1 may play a positive role in CLL progression.

\section{Acknowledgements}

We are grateful to Dr Anders Rosén (Linköping University, Sweden) for generously providing HG3 cells. The present study was supported by the National Natural Science Foundation of China (81400127), the National Natural Science Foundation of China (81201264), the National Natural Science Foundation of China (81200376) and the Certificate of China Postdoctoral Science Foundation Grant (2015M571818).

\section{References}

1. Malek SN: The biology and clinical significance of acquired genomic copy number aberrations and recurrent gene mutations in chronic lymphocytic leukemia. Oncogene 32: 2805-2817, 2013.

2. Zhu DX, Zhu W, Fang C, Fan L, Zou ZJ, Wang YH, Liu P, Hong M, Miao KR, Liu P, et al: miR-181a/b significantly enhances drug sensitivity in chronic lymphocytic leukemia cells via targeting multiple anti-apoptosis genes. Carcinogenesis 33: 1294-1301, 2012.
3. Bianchi S, Dighiero G and Pritsch O: Selected topics in chronic lymphocytic leukemia pathogenesis. In: Chronic Lymphocytic Leukemia. InTech, Rijeka, pp3-18, 2012.

4. Wójtowicz M and Wołowiec D: Dysregulation of apoptosis and proliferation in CLL cells. In: Chronic Lymphocytic Leukemia. InTech, Rijeka, pp37-62, 2012.

5. Wang P, Pavletic ZS and Joshi SS: Increased apoptosis in B-chronic lymphocytic leukemia cells as a result of cyclin D3 down regulation. Leuk Lymphoma 43: 1827-1835, 2002.

6. Razavi R, Gehrke I, Gandhirajan RK, Poll-Wolbeck SJ, Hallek M and Kreuzer KA: Nitric oxide-donating acetylsalicylic acid induces apoptosis in chronic lymphocytic leukemia cells and shows strong antitumor efficacy in vivo. Clin Cancer Res 17: 286-293, 2011.

7. Halina A, Artur P, Barbara MK, Joanna S and Anna D: Alterations in TP53, cyclin D2, c-Myc, p21WAF1/CIP1 and p27KIP1 expression associated with progression in B-CLL. Folia Histochem Cytobiol 48: 534-541, 2010.

8. Decker T, Hipp S, Ringshausen I, Bogner C, Oelsner M, Schneller F and Peschel C: Rapamycin-induced G1 arrest in cycling $\mathrm{B}-\mathrm{CLL}$ cells is associated with reduced expression of cyclin D3, cyclin E, cyclin A, and survivin. Blood 101: 278-285, 2003.

9. Decker T, Schneller F, Hipp S, Miething C, Jahn T, Duyster J and Peschel C: Cell cycle progression of chronic lymphocytic leukemia cells is controlled by cyclin D2, cyclin D3, cyclindependent kinase (cdk) 4 and the cdk inhibitor p27. Leukemia 16: 327-334, 2002.

10. Damle RN, Calissano C and Chiorazzi N: Chronic lymphocytic leukaemia: A disease of activated monoclonal B cells. Best Pract Res Clin Haematol 23: 33-45, 2010.

11. Sainz-Perez A, Gary-Gouy H, Gaudin F, Maarof G, MarfaingKoka A, de Revel T and Dalloul A: IL-24 induces apoptosis of chronic lymphocytic leukemia B cells engaged into the cell cycle through dephosphorylation of STAT3 and stabilization of p53 expression. J Immunol 181: 6051-6060, 2008.

12. Caligaris-Cappio F and Ghia P: Novel insights in chronic lymphocytic leukemia: Are we getting closer to understanding the pathogenesis of the disease? J Clin Oncol 26: 4497-4503, 2008.

13. Soma LA, Craig FE and Swerdlow SH: The proliferation center microenvironment and prognostic markers in chronic lymphocytic leukemia/small lymphocytic lymphoma. Hum Pathol 37: $152-159,2006$.

14. Schwechheimer C and Deng XW: The COP/DET/FUS proteinsregulators of eukaryotic growth and development. Semin Cell Dev Biol 11: 495-503, 2000.

15. Yi C, Wang H, Wei N and Deng XW: An initial biochemical and cell biological characterization of the mammalian homologue of a central plant developmental switch, COP1. BMC Cell Biol 3: 30, 2002

16. Yi C and Deng XW: COP1 - from plant photomorphogenesis to mammalian tumorigenesis. Trends Cell Biol 15: 618-625, 2005.

17. Marine JC: Spotlight on the role of COP1 in tumorigenesis. Nat Rev Cancer 12: 455-464, 2012.

18. Wei W and Kaelin WG Jr: Good COP1 or bad COP1? In vivo veritas. J Clin Invest 121: 1263-1265, 2011.

19. Wertz IE, O'Rourke KM, Zhang Z, Dornan D, Arnott D, Deshaies RJ and Dixit VM: Human De-etiolated-1 regulates c-Jun by assembling a CUL4A ubiquitin ligase. Science 303: 1371-1374, 2004.

20. Dornan D, Wertz I, Shimizu H, Arnott D, Frantz GD, Dowd P, O'Rourke K, Koeppen H and Dixit VM: The ubiquitin ligase COP1 is a critical negative regulator of p53. Nature 429: 86-92, 2004.

21. Vitari AC, Leong KG, Newton K, Yee C, O'Rourke K, Liu J, Phu L, Vij R, Ferrando R, Couto SS, et al: COP1 is a tumour suppressor that causes degradation of ETS transcription factors. Nature 474: 403-406, 2011.

22. Qi L, Heredia JE, Altarejos JY, Screaton R, Goebel N, Niessen S, Macleod IX, Liew CW, Kulkarni RN, Bain J, et al: TRB3 links the E3 ubiquitin ligase COP1 to lipid metabolism. Science 312: 1763-1766, 2006.

23. Dentin R, Liu Y, Koo SH, Hedrick S, Vargas T, Heredia J, Yates J III and Montminy M: Insulin modulates gluconeogenesis by inhibition of the coactivator TORC2. Nature 449: 366-369, 2007. 
24. Kato S, Ding J, Pisck E, Jhala US and Du K: COP1 functions as a FoxO1 ubiquitin E3 ligase to regulate FoxO1-mediated gene expression. J Biol Chem 283: 35464-35473, 2008.

25. Dornan D, Bheddah S, Newton K, Ince W, Frantz GD, Dowd P, Koeppen H, Dixit VM and French DM: COP1, the negative regulator of $\mathrm{p} 53$, is overexpressed in breast and ovarian adenocarcinomas. Cancer Res 64: 7226-7230, 2004.

26. Lee YH, Andersen JB, Song HT, Judge AD, Seo D, Ishikawa T, Marquardt JU, Kitade M, Durkin ME, Raggi C, et al: Definition of ubiquitination modulator COP1 as a novel therapeutic target in human hepatocellular carcinoma. Cancer Res 70: 8264-8269, 2010.

27. Li YF, Wang DD, Zhao BW, Wang W, Huang CY, Chen YM, Zheng Y, Keshari RP, Xia JC and Zhou ZW: High level of COP1 expression is associated with poor prognosis in primary gastric cancer. Int J Biol Sci 8: 1168-1177, 2012.

28. Yoshida A, Kato JY, Nakamae I and Yoneda-Kato N: COP1 targets $\mathrm{C} / \mathrm{EBP} \alpha$ for degradation and induces acute myeloid leukemia via Tribl. Blood 122: 1750-1760, 2013.

29. Migliorini D, Bogaerts S, Defever D, Vyas R, Denecker G, Radaelli E, Zwolinska A, Depaepe V, Hochepied T, Skarnes WC, et al: Cop1 constitutively regulates c-Jun protein stability and functions as a tumor suppressor in mice. J Clin Invest 121: 1329-1343, 2011.
30. Rosén A, Bergh AC, Gogok P, Evaldsson C, Myhrinder AL, Hellqvist E, Rasul A, Björkholm M, Jansson M, Mansouri L, et al: Lymphoblastoid cell line with B1 cell characteristics established from a chronic lymphocytic leukemia clone by in vitro EBV infection. Oncoimmunology 1: 18-27, 2012.

31. Pekarsky Y, Zanesi N and Croce CM: Molecular basis of CLL. Semin Cancer Biol 20: 370-376, 2010.

32. Wolowiec D, Wojtowicz M, Ciszak L, Kosmaczewska A Frydecka I, Potoczek S, Urbaniak-Kujda D, Kapelko-Slowik K and Kuliczkowski K: High intracellular content of cyclindependent kinase inhibitor $\mathrm{p} 27^{\mathrm{Kip} 1}$ in early- and intermediate stage B-cell chronic lymphocytic leukemia lymphocytes predicts rapid progression of the disease. Eur J Haematol 82: 260-266, 2009.

33. Giné E, Martinez A, Villamor N, López-Guillermo A, Camos M, Martinez D, Esteve J, Calvo X, Muntañola A, Abrisqueta P, et al: Expanded and highly active proliferation centers identify a histological subtype of chronic lymphocytic leukemia (accelerated chronic lymphocytic leukemia) with aggressive clinical behavior. Haematologica 95: 1526-1533, 2010.

34. Huang $\mathrm{H}$ and Tindall DJ: Dynamic FoxO transcription factors. J Cell Sci 120: 2479-2487, 2007. 